Cuarteiro J., Cabaleiro M., Sousa H.S., Branco J.M. (2019) Tridimensional parametric model for prediction of structural safety of existing timber roof using laser scanner and drilling resistance tests. Engineering Structures 185. pp 58-67 (doi.org/10.1016/j.engstruct.2019.01.096)

\title{
TRIDIMENSIONAL PARAMETRIC MODEL FOR PREDICTION OF STRUCTURAL SAFETY OF EXISTING TIMBER ROOFS USING LASER SCANNER AND DRILLING RESISTANCE TESTS
}

\author{
Jaime Cuartero $^{1}$, Manuel Cabaleiro ${ }^{1 *}$, Hélder S. Sousa ${ }^{2}$, Jorge M. Branco ${ }^{2}$ \\ ${ }^{1}$ Department of Materials Engineering, Applied Mechanics and Construction, School of Industrial \\ Engineering, University of Vigo, C.P. 36208, Vigo, Spain. \\ ${ }^{2}$ ISISE, Department of Civil Engineering, University of Minho, 4800-058 Guimarães, Portugal \\ *Corresponding author: mcabaleiro@uvigo.es; tel: +34 986813659 . Fax: +34 986813663
}

\begin{abstract}
Heritage timber structures are found worldwide evidencing intricate configurations, not only due to the arrangement between elements, which sometimes leads to complex connections with hidden elements, but also due to elements with variable cross-sections and often with signs of decay. Due to its historical value, the structural safety of these structures must be assessed periodically and the conservation state verified. The presence of decay and the resulting reduction of effective cross-section must be assessed both at the present time as well as its probable evolution in the future if no intervention is made. Due to this need, in the present work, a methodology is proposed to analyse the structural safety of timber structures using tridimensional parametric models where the geometry of the cross-section of each element is a variable regarding the presence of decay. The model allows to determine the structure's volume more accurately, to identify the present condition of the structure and make predictions of possible future decay scenarios. Information obtained by laser scanner and drilling resistance tests are considered as prior information for the model. As to demonstrate the validity of the proposed methodology, the creation of a tridimensional parametric model is applied to a case study corresponding to the timber ceiling structure of the Knights' Room of the Convent of Christ in Portugal.
\end{abstract}

Keywords: Parametric model, timber, decay, resistant cross-section, LIDAR, drilling resistance tests 


\section{INTRODUCTION}

Presently, there is a large quantity of old timber structures that have intricate geometries with elements having irregular cross-section. This renders a structural safety assessment a complex task. Moreover, due to several years of exposition to decay agents and often with inadequate maintenance conditions, these structures may be at risk of collapse. Therefore, it is of extreme importance to accurately define the present condition of the structure, but even more to predict probable scenarios which may help on the determination of maintenance plans or interventions.

The intricate geometry of these structures makes the onsite measurements difficult which then may lead to an inaccurate definition of structural numerical models. An exact definition of the self-weight of these structures is also a challenge due to its complex geometry. Moreover, decorative elements have elaborate configurations which makes it difficult to calculate an exact volume. On the other hand, the apparent volume must be combined with information of the structure decay level, in order to obtain the effective resistant section of the elements and how its reduction may influence its structural behaviour in the future.

Nowadays, techniques such laser scanner allows to measure the geometry without a direct contact to the structure, only requiring that the structure is within the visible range of the equipment. Laser scanner is a procedure that is acquiring more and more importance, as it is a straightforward way to obtain the shape of an object, element or structure easily and in a short time. The result of these measurements is a cloud of points that allows to represent in 3D all elements that are around the laser scanner. Laser scanner has been employed in several types of structures to obtain information for structural models, where timber buildings have also been analysed. For example, Alessandri et al. [1] and Macchioni et al. [2], have made a 3D model of Bethlehem's Nativity Church. In that model, preliminary structural analyses were made aiming at the vulnerability estimation of the building subjected to different load combinations (i.e. self-weight, snow, wind and seismic action). The analyses included mainly walls and columns, but also timber roof beams. Non-destructive tests were combined and used in this work to assess the timber beams of the building [2]. In Bertolini-Cestari et al. [3] a study of the main room of the Valentino Castle in Turin, Italy, was performed. A 3D model was used including laser scanning and digital close range photogrammetry as prior information. Also, some of the ribs of the vault were tested by drilling resistance tests. Finally, finite element numerical 
simulations of the dome were carried out and the results led to the definition of a maintenance plan. Further work on this structure was made using laser scanning surveying combined with non-destructive tests and numerical simulations [4], in order to assess the efficiency of an intervention and the condition of the joints. In the same city, the work of [5] describes the evaluation of a timber floor belonging to a historic residential building, according to the results of laser scanner to determine the deflection of the structure.

In Bassier et al [6], a 3D modelling of a castle timber roof in the city of Mechelem (Belgium) was performed from information obtained by laser scanner data. Two 3D models and structural analysis were made, one in wire-frame-model and the other using a mesh model. The results showed that variations in geometry led to important differences on the structural behaviour of the timber roof. Pöchtrager et al. [7] presented a methodology and corresponding tools needed to process point clouds from laser scanning data, from which linear beams of timber roof structures could be assessed. This method was used in the 3D models of several timber roof structures of the Vienna Imperial Palace. In Brashaw et al. [8] a three-dimensional laser scanner was used to determine the dimensions and visual condition of a historic bridge, supporting that this method can be used for a variety of purposes including as-built documentation and structural assessment, while also providing detail on the land topography adjacent to the structure. Moreover, in that study it was proposed that laser scanning technology should be incorporated into a comprehensive inspection protocol for timber structures, where visual inspection and non-destructive testing can be combined to it.

Other works on 3D modelling of timber buildings have been performed such as Betti et al. [9], where an analysis about the seismic and static behaviour of the basilica of Santa Maria all'Impruneta (Italy) was performed. These analyses included mainly masonry elements, but also a timber roof. On the other hand, Oreni et al. [10] showed the usefulness of Historic Building Information Modelling (HBIM) to support conservation and management of built heritage. These HBIM can be performed using information obtained from laser scanner data. Cabaleiro et al. [11] presented a methodology to use laser scanner data to model timber beams in $3 \mathrm{D}$ and to use that information in a corresponding structural model. This methodology automatically finds the geometrical properties of cross-sections of highly irregular timber beams. Based on that methodology, Cabaleiro et al. [12] developed an algorithm that automatically calculates the 
deformations of highly irregular timber structures from laser scanner, whereas Cabaleiro et al. [13] provided a solution to automatic detection of cracks in timber beams from laser scanner data. However, the possibility of analysing the evolution of decay and loss of effective cross-section through the creation of 3D parametric models that allow to assess the structural safety of a timber structure along time has not yet been fully addressed.

The state of conservation of timber elements has been assessed with help of non or semidestructive tests, either individual or by a combination of several methods [14][15]. Among those methods, drilling resistance tests are an option when a local assessment of the decay depth is of importance. Drilling resistance tests consist in the advance of a drill through the timber element's cross-section at a given speed. The amount of energy, required to maintain that speed at a constant value, is measured along the test. Lower values of required energy mean that the material is offering less resistance to the drill advance which can be, for instance, a sign of decay presence. Drilling resistance tests have been made to assess the onsite conditions of timber elements in several recent works, such as in Ilharco et al. [16], Nowak et al. [17], Branco et al. [18], Frontini [19], and Bergamasco et al. [20]. Although drilling resistance is a local test, if several measurements are made in different points of the same cross-section it is possible to surmise an effective cross-section by knowing the decay depth on each of those points, as obtained in Lourenço et al. [21] and Branco et al. [18].

Laser scanner measurements are limited to visible surfaces, which in timber structures may be a limitation as often there are non-accessible spaces and non-visible surfaces. In these cases, it may be possible to complete this geometrical survey with educated guesses from experts by assumption of similar elements of the same structure. However, this leads to a great uncertainty in the measurements. In Cabaleiro et al. [22], drilling resistance tests were combined with laser scanner to better define the geometry of timber beams even if one of the surfaces was not visible.

Timber decay is a complex phenomenon that depends not only on the wood species and environmental conditions, but also to the construction details and overall exposure to damp, as well as to the preventive and maintenance actions or lack of them during the structure's lifetime. Values for decay rates that may help on planning and defining future interventions or maintenance actions were calculated in several works such as those of Lourenço et al. [21], Brites et al. [23], or Sousa et al. [24] either based on experimental results or reliability simulation. The calculation of these decay rates were based on the 
predictive models proposed by Leicester [25] and Leicester et al. [26]. A premise of those models is that non-decayed wood suffers no strength loss and that the decay zone progresses along the longitudinal axis and within the cross-section width. The decay phenomenon is represented by an idealized model given by a bilinear function with the two parameters corresponding to the time before noticeable decay starts and an annual decay penetration rate. In its turn, the decay penetration rate depends on climate conditions (mainly temperature and relative air humidity), durability (wood species) and structural conditions of the timber element (thickness, width, connectors and global geometry).

With respect to the combination of laser scanner and drilling resistance tests, the work of Cabaleiro et al. [22] has proposed a methodology to assess the geometry of irregular cross-section timber beams with non-visible faces and affected by decay. However, this work still does not comprise the creation of $3 \mathrm{D}$ parametric models where the geometry is an input variable.

According to the described limitations and challenges, the objective of the present work is to define a methodology for the creation of 3D parametric models for assessment of the structural safety of existing timber roofs with intricate geometries and affected by decay, using a combination of laser scanner data and drilling resistance tests. This 3D parametric model further allows to simulate different decay situations and from that to predict the structural performance of the structure in future scenarios.

\section{METHODOLOGY}

The methodology proposed in this work combines information from laser scanner and drilling resistance tests to create a database of prior information for $3 \mathrm{D}$ parametric models. The database obtained by these tests is used to create the models where the main variable parameter is the dimension of the cross-section of each element that depends on the level of decay, either the existent or the predicted. The steps of the methodology are presented in Figure 1 and detailed in the following topics. The applied methodology is also applicable to roofs where the bottom and upper sides of the roof are not visible simultaneously. 


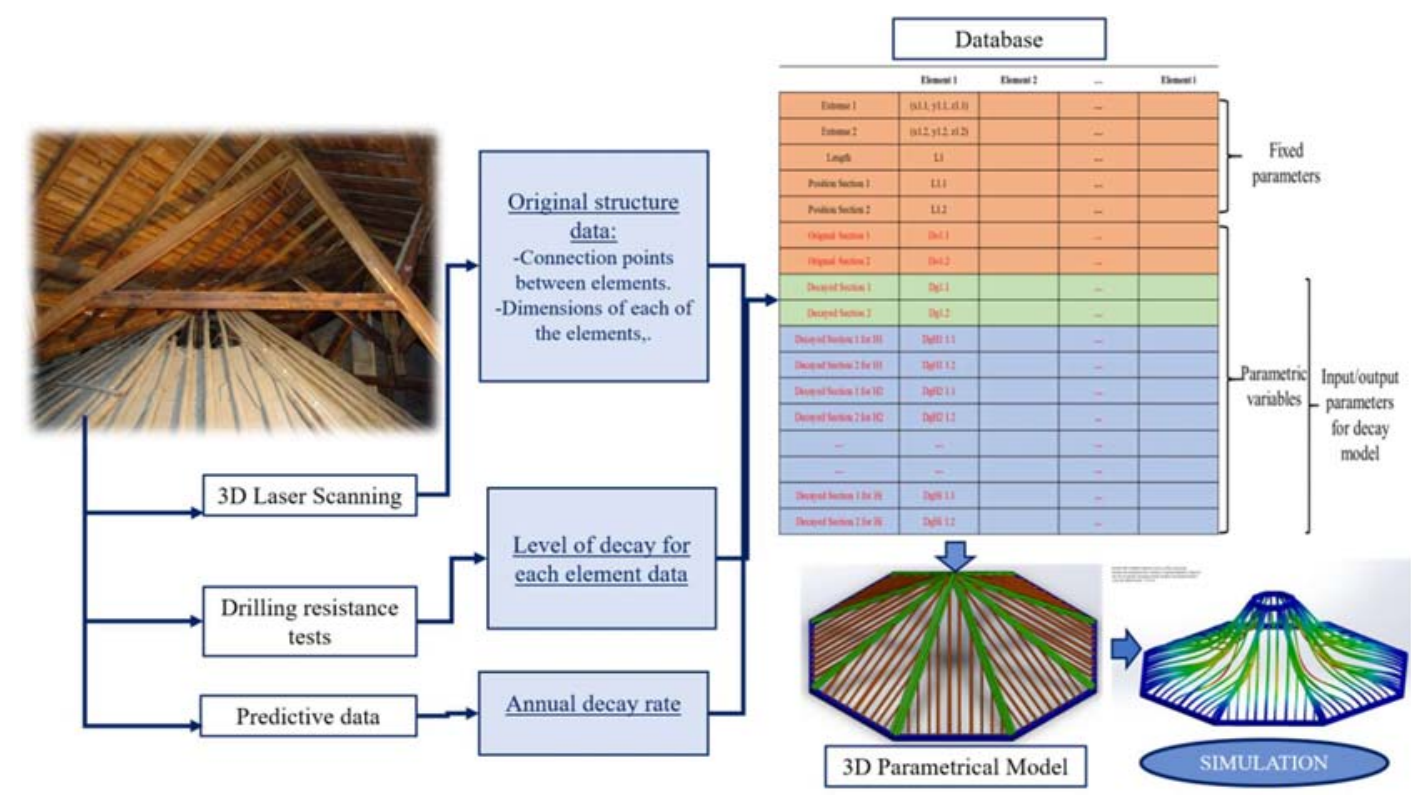

Figure 1: Framework of the proposed methodology.

\subsection{Laser scanner measurements}

In the first step of the methodology, the full geometrical survey of the timber structure is made using the laser scanner technique. The laser scanning is made to both the upper and lower sides of the roofs which are not visible at the same time. The number of measurements depends on the geometry of the roof and accessibility. After, both clouds of points, upper and lower faces, are combined into a single cloud of points using a unique reference system given by different targets which location and distance between them are known at priori. With these measurements it is possible to obtain all the geometric variables of the structure which are visible and also to calculate the full volume of the structure, which can further be used to estimate the self-weight of the structure.

With the complete cloud of points, the coordinates of the points corresponding to the intersection of the different elements that compose the structure are obtained. Also the value of length of each element and the exterior cross-section dimensions of each element along their lengths are obtained. In this method, special attention is given to the crosssections where drilling resistance tests will after be made.

All measurement results obtained in this step are stored in a database that will later be coupled to the tridimensional model. In this step, the geometrical measurements are only correspondent to the apparent section which is visible to the laser scanner. Therefore, 
decay depth and consequent loss of effective cross-section are not yet assumed into the model.

\subsection{Drilling resistance tests}

After compiling the information regarding the exterior geometry of each element, drilling resistance tests are made to specific points of the elements to determine their decay level and consequent effective cross-section (i.e. cross-section of the element without consideration of the decayed area). Each measurement is referenced in the global coordinate system of the cloud of points by identifying the entry and exit points of the drill head during the tests. Similar procedure was detailed in Cabaleiro et al[22]. To fully define the decay level of the structure, ideally all elements should be tested and preferably on different locations along the length of the element.

The results obtained from the drilling resistance test, in this step, are attached to the information already stored in the database, which after will be compiled in the tridimensional model. In this step, the geometrical measurements correspond to the depth of decay of each element, which is subtracted to the apparent cross-section to obtain the residual cross-section that corresponds to the effective cross-section along the element's length.

\subsection{Predictive data}

In this step, the effect of decay is taken in account on the safety assessment of the timber structure considering the reduction of effective cross-section. A set of numerical simulations is made aiming at defining the critical elements of the structure and what level of decay would lead to failure, either local or global failures. After obtaining the critical value of decay depth and by combining that information with predictive decay models it is possible to infer on probable residual lifetime periods for the structure, if the environmental conditions maintain constant and favourable to the advance of decay. The decay rate is a parameter which gives the value of loss of cross-section thickness on a given period of time. If both the decay rate and the critical reduction of effective crosssection are known, it is possible to obtain an estimation of the time needed to reach failure due to decay. 


\subsection{Tridimensional parametric model}

The tridimensional parametric model is generated based on the database of information compiled in the previous steps. This model is used to simulate the performance of the structure in different conditions and for distinct lifetime periods. The different conditions are obtained by changing the value of the variables in the database. The database gathers fixed parameters, such as length of each element and location (coordinates of the start and end points of each element), and variable parameters such as the cross-section geometry (area and inertia) that are dependent on the level of decay.

In this point, the load conditions are also assumed in the model. Self-weight is derived from the geometry of the structure obtained by the combination of the laser scanner cloud of points, whereas exterior loads are estimated based on the conditions found onsite.

\section{CASE STUDY}

A case study was considered to verify the applicability of the proposed methodology. The case study corresponds to the analysis of the timber roof structure of the Knights' Room of the Convent of Christ in Portugal. This historic monument is located in the city of Tomar which was constructed under the orders of Dom Gualdim Pais, a Knights Templar, in the late 12th century (Figure 2). Although the convent was founded in the late 12th century, its construction only finished on the $17^{\text {th }}$ century, thus posing this monument with several architectonic styles and trends such as Romanesque, Gothic, Renaissance and Manueline. The Convent of Christ is an UNESCO World Heritage Site since 1983 and one of the most iconic monuments in Portugal. The Knight's Room is presently not opened to regular tourist visits as it is being under analysis for maintenance and possible intervention. Its ceiling is an example of an intricate carpentry work both structurally, as well as in terms of decoration, and will be the focus of this case study analysis, geometric survey and numerical simulation. The main structural members of this ceiling are made of chestnut (Castanea Sativa Mill.) elements. 


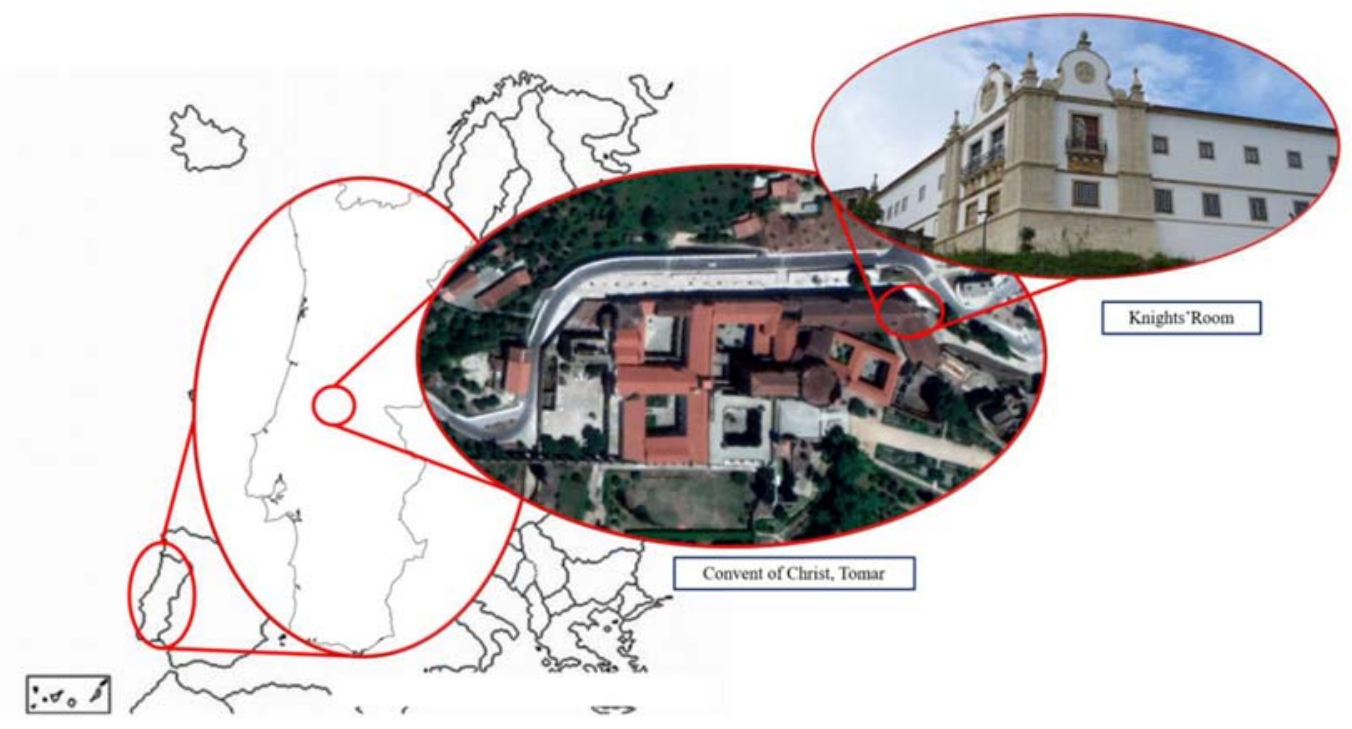

Location of the Knights' Room in the Convent of Christ, Tomar, Portugal. Aereal photograph retrieved from Google maps at July 2018

Figure 2. Location of the Knights' Room in the Convent of Christ, Tomar, Portugal

Besides the decorated ceiling and the vault that supports it, there is a more recent timber structure that supports the roof covering and protects the older structure from the outside environment (Figure 3). This more recent structure will not be analysed by the proposed method as its geometry is regular and the cross-sections do not present significant decay.

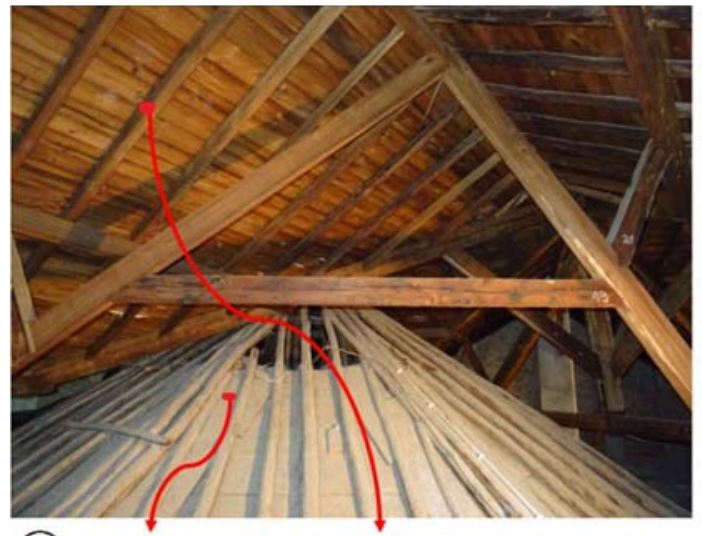

(a) Old structure

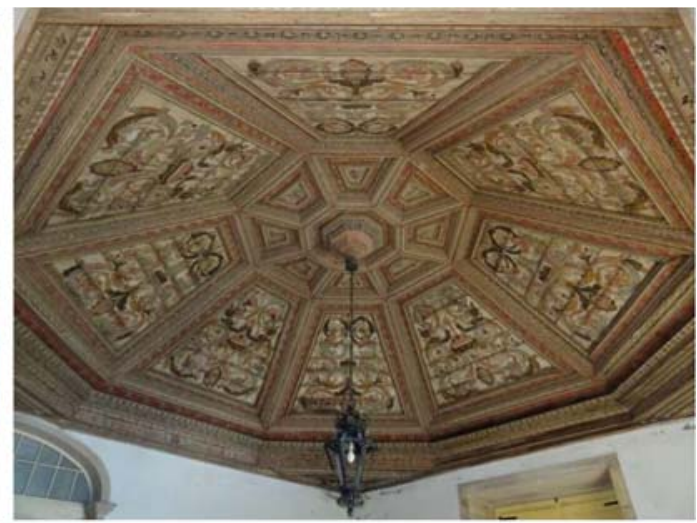

(b)

Figure 3. Knights' Room roof structure: a) Top view of the support structure of the decorative ceiling and a more recent timber roof; b) Bottom view from inside the Knights' Room. 
Aiming at the analysis of the older timber ceiling structure, the following steps were taken according to the proposed methodology: i) geometric survey by laser scanner; ii) drilling resistance tests for decay assessment; iii) predictive data for parametric model; and, iv) simulation using a tridimensional parametric model. Each step is now described according to the work made for this specific case study.

\subsection{Geometric survey by laser scanner}

The equipment used to conduct the geometric survey was a laser scanner FARO Focus $3 \mathrm{D}$ able to take measurements with a range of 0.6-120 $\mathrm{m}$ with a precision of $\pm 2 \mathrm{~mm}$ at $25 \mathrm{~m}$ distance with normal light and reflection conditions. The measurement angle range is $360^{\circ}$ horizontal and $305^{\circ}$ vertical with a maximum angular resolution of $0.009^{\circ}$.

Initially, five scanning positions were considered for measuring the bottom side of the ceiling structure visible from the interior of the Knights' Room (Figure 4a). After, twenty locations were used for scanning the top side of the ceiling structure (Figure 4b). The different number of measurements derive from the need to make a sufficient number of measurements that would allow to obtain information of all the faces of the octagonal ceiling structure which had more physical obstacles on the top side. The number of measurements was also conditioned by the requirement that all the beams had to be assessed by laser scanner on all of its visible faces. All measurements made to each side view (top or bottom views) were combined into separate clouds of points with its own reference system.

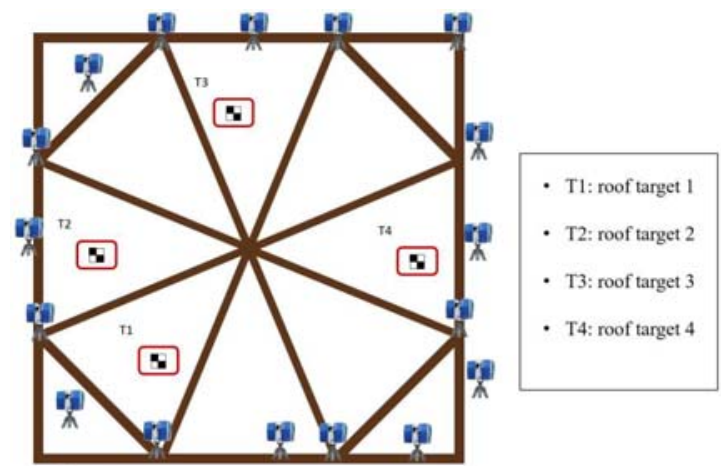

(a)

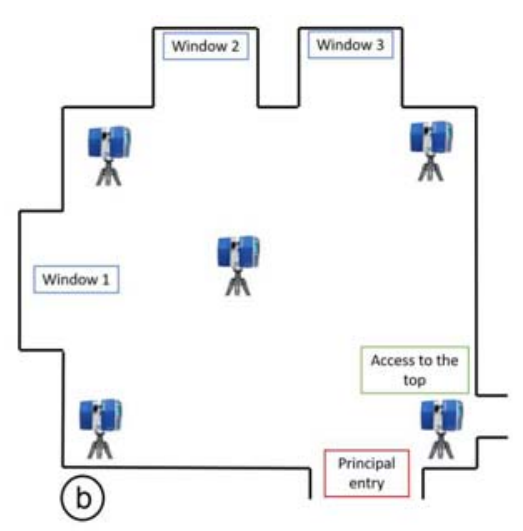

(b)

Figure 4. Location of laser scanner measurements: a) top side of the ceiling; b) bottom side from the interior of the Knights' Room; 
In this step, besides obtaining the geometric survey of the apparent surface of each element, also the volume of the structure was obtained in order to have a more reliable estimation of the self-weight of the structure. For existing structures with intricate geometric configurations, often the volume of the structure is obtained by simplified methods that may lead to significant errors.

In this work, an initial estimation of the volume is made and after compared to the results obtained by a more rigorous geometric survey made by the laser scanner. The initial estimation of the volume was made considering a constant thickness of the ceiling covering boards and constant cross-section for the main structural elements as obtained in a simplified geometric model (Figure 5). This model is based on onsite measurements made using simple measuring tapes, laser meters (for length of the elements) and calipers (for cross-section geometry measurements). At this stage, smaller decorative elements were not considered in the calculation of the total volume for the simplified model.
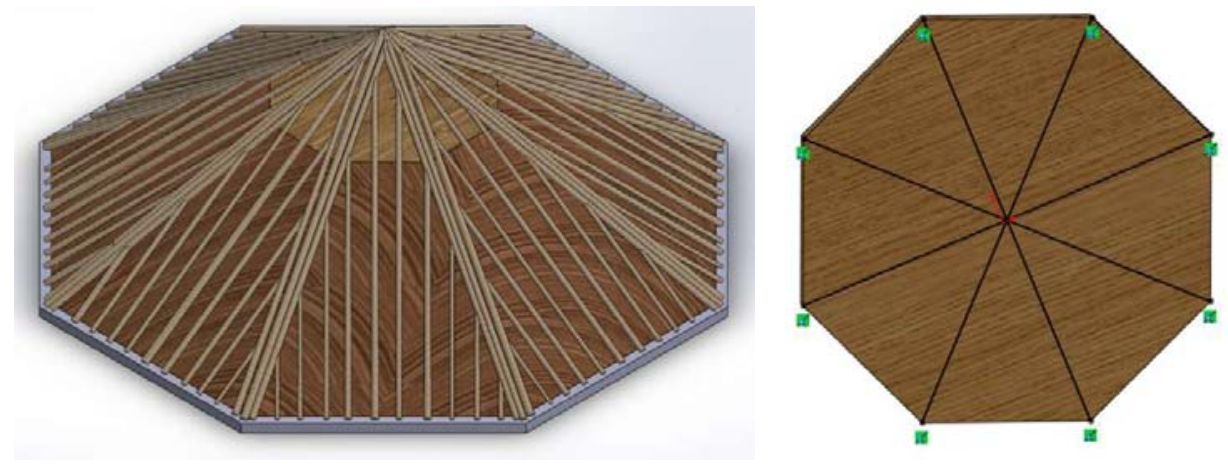

Figure 5. Simplified geometry for the ceiling structure.

To obtain a more precise estimation of the global volume of the structure, the data obtained using the laser scanner measurements is used. The main issue concerning this estimation is to find a common reference system that may combine the cloud of points obtained from the top and bottom sides of the ceiling. To solve this issue, a system of targets was made using a rigid metallic rod with two targets fixed to each end. The rod with a known length was fixed to the covering boards where small holes existed, due to the presence of decay, and permitted to pass the rod through the top side to the bottom 
side. After fixing the metallic rod, the two targets were placed on each end (Figure 6). The rod was aligned with the vertical direction of the global reference system. A total of four rods were placed in different positions of the ceiling. With this information, the two cloud of points were combined by locating the targets of the rods (both from the top and bottom sides) and after by spacing those clouds of points with the value corresponding to the length of the rods. To calculate the volume, the combined cloud of points was then converted to a solid through a meshing process (Figure 6).

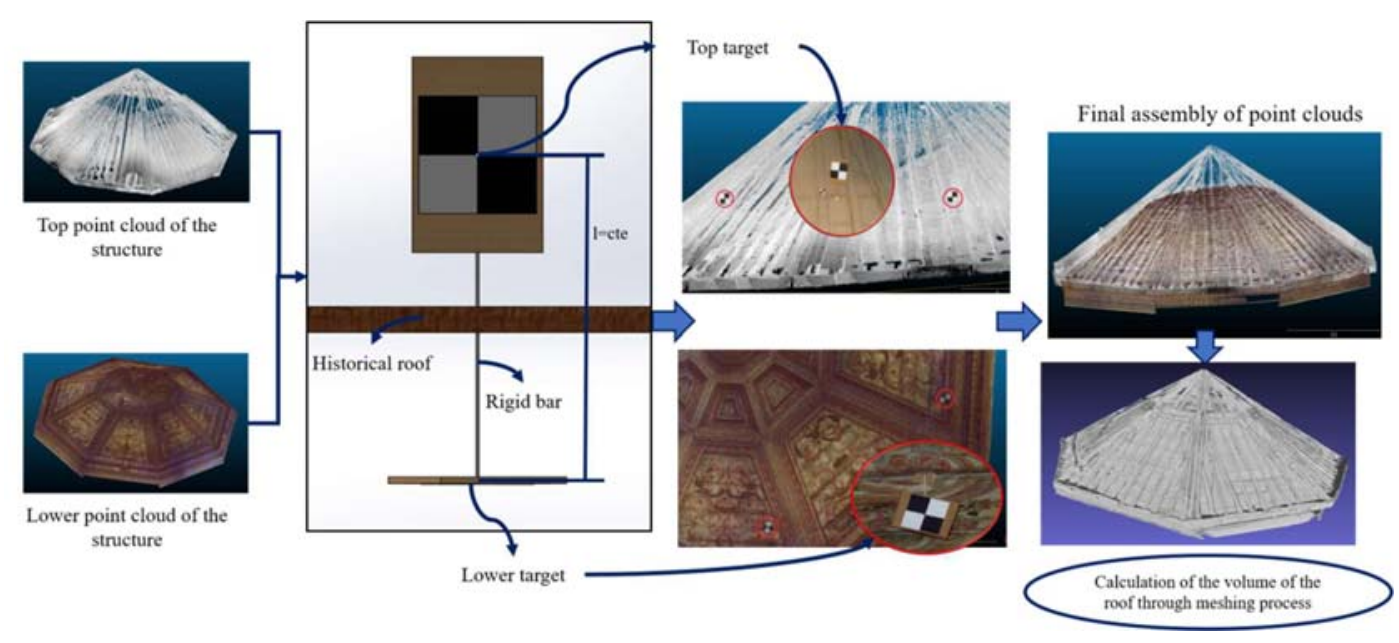

Figure 6. Schematic of the application of the rods with double target to combine the cloud of points and obtain a solid for volume calculation.

With the global cloud of points, a complete description of the geometrical parameters was obtained, namely the apparent cross-section of each element and its variation along its length, the length of the element and the coordinate points of each intersection between elements. This method allowed to obtain the thickness of the decorative panels by measuring the distance between points of the upper and lower clouds of points. The thickness of the beams was obtained through laser scanner made from the upper side and assuming that the lower surface of the beams was in contact with the decorative panels. This information is after compiled in the database and used to build the tridimensional numerical model. The length of the element and intersection between elements are considered as fixed parameters whereas the cross-section dimensions are implemented in the database as parametric variables which can be changed when a certain condition is considered (e.g. apparent cross-section or effective cross-section). The complete definition of the cross-section geometry is obtained by combining the information of the 
laser scanner (visible faces) with the information of the drilling resistance tests (for hidden faces) according to the method used in Cabaleiro et al.[22].

\subsection{Drilling resistance tests}

The drilling resistance tests were made with a Resistograph $₫ 3450$ equipment, which has a drilling needle with $3 \mathrm{~mm}$ diameter at the cutter of the drill bit and $1.5 \mathrm{~mm}$ diameter along the shank. The drilling needle progresses at a constant speed of $30 \mathrm{~cm} / \mathrm{min}$, turning at $1500 \mathrm{rpm}$. The measurements were made to the structural elements accessible by the top side of the timber ceiling. Each beam was measured on its lower segment at a distance of $25 \mathrm{~cm}$ from the its end. For each face, the three longer beams were also tested at their mid span segment. For each cross-section a perpendicular measurement (entry point on the top side of the cross-section) and an inclined measurement (entry and exit points at the lateral faces of the cross-section) were made. The inclined measurement was made with a $25^{\circ}$ angle due to the lack of accessibility of that face when performing the drilling resistance tests. These locations were considered except when a visible defect (such as a knot) was located on those sections. In that case, the measurement was made on a nearby segment without influence of defects. The lower and middle segments of the beams were tested due to its easy access, as it was not required to build any framework to reach these segments, and also as they were the segments that, through visual inspection, presented higher signs of decay. Overall, approximately 250 drilling resistance tests were made. It must be noted that the perpendicular measurement was made until a drop of resistance corresponding to the interface between beams and decorative panels was observed, in order to avoid damage to the panels. Therefore, no exit holes were made on the panels. All visible entry and exit points were marked with small targets that were identified in the point cloud (Figure 7c).

By carrying out the drilling resistance tests, the effective cross-section of each of the beams was obtained, in the same points where the apparent section was measured in the point cloud. The depth of decay of each section was entered into the database as parametric data linked to each of the beams of the numerical model. 


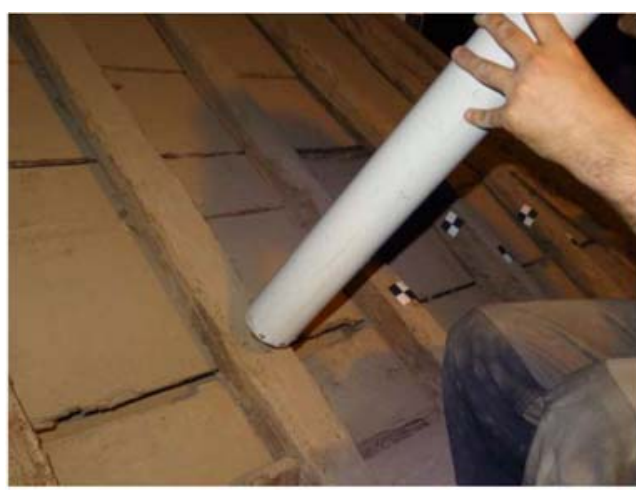

a)

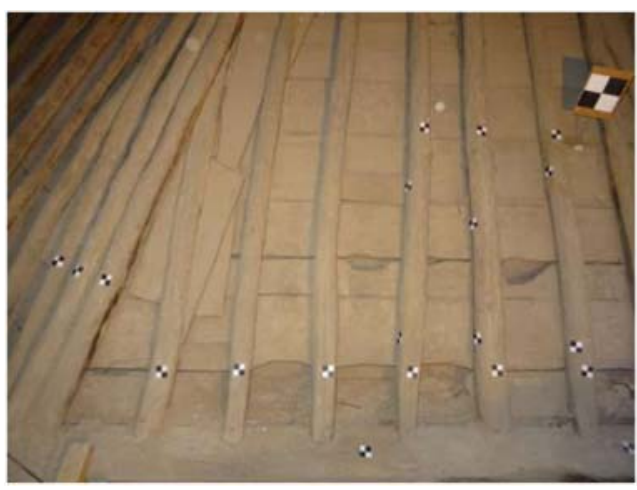

b)

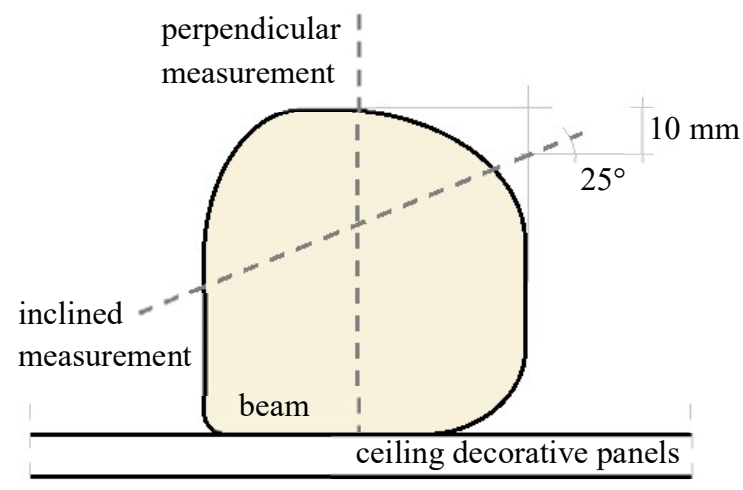

c)

Figure 7. Drilling resistance tests: a) test; b) target placement for entry and exit points; c) cross-section schematic of drilling resistance measurements.

\subsection{Predictive data}

The reduction of effective cross-section was implemented in the parametric database by reducing the height and width of each element. The reduction corresponded to the simulation of decay occurring for different periods of time. The severity of decay depends on the environmental conditions, exposure, type of structure and wood species.

In this work, the values of decay depth are known for different cross-sections of the elements where the drilling resistance tests were made. Decay models, according to Leicester [25] and Leicester et al. [26] were used to simulate the effect of cross-section reduction along time and to predict the behaviour of the structure in the future and a decay rate was chosen regarding a study made to elements of the same wood species with similar exposure conditions [24]. 


\subsection{Tridimensional parametric model}

The 3D parametric model was made regarding the geometric survey information obtained in the previous steps and the self-weight of the structure is applied according to the volume obtained from the combined cloud of points. While the apparent geometry is given by the laser scanner survey, the reduction of the cross-section is made according to the results of the drilling resistance tests.

This parametric model will be the basis for simulation of different conditions and for structural assessment (Figure 8). With this model the following simulations were made: i) apparent structure considering all the cross-section as resistant section; ii) existing structure with the reduction of resistant cross-section corresponding to the drilling resistance tests; iii) existing structure with the reduction of cross-section and constant decay progress in all the elements of the structure; and, iv) existing structure with the reduction of cross-section and constant decay progress in one of the faces of the structure.

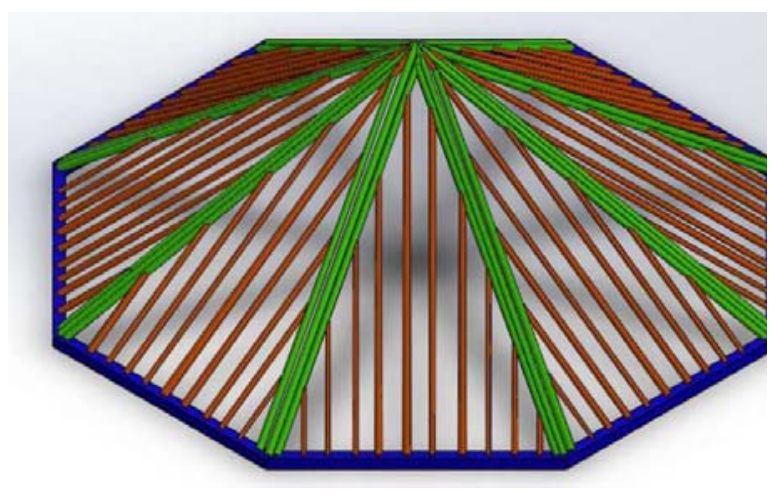

a)

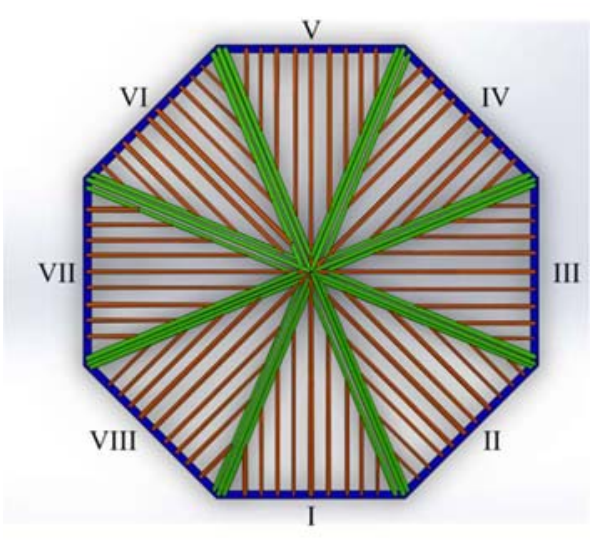

b)

Figure 8. 3D parametric model: a) perspective b) indication of the faces that form the structural octagonal.

The simulation considering the reduction of the cross-section, assuming a decay phenomenon of all structure, was made by decreasing the area of the cross-section homogeneously on all elements of the structure independently of the present level of 
decay. The simulation regarding decay on a single face was made as it is common not to have a homogenous decay phenomenon on all elements of a same structure, due to different boundary and exposure conditions. In that simulation, the face that exhibited a higher level of decay in the drilling resistance tests was considered. Actually, this was confirmed by visual inspection made onsite, where face VI presented more evident signs of decay progress, as well as signs of water accumulation (Figure 9).

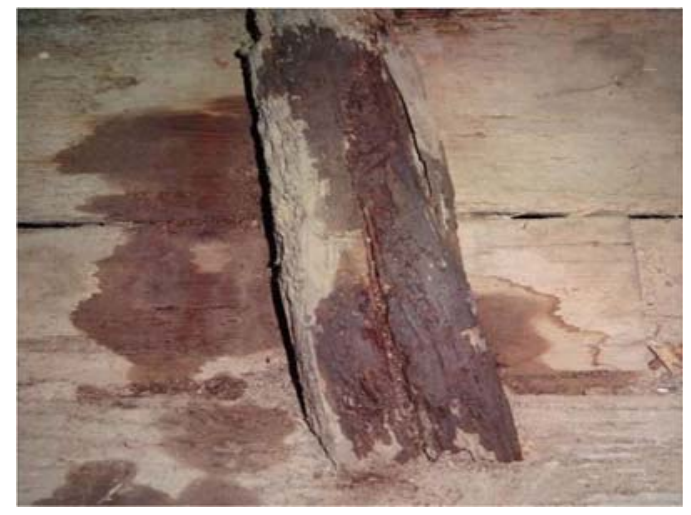

Figure 9. Presence of water signs in the most decayed face of the timber ceiling.

The model measured the level of stress and deformation of the structure in order to analyse both ultimate and service limit states for each of the simulations. Limit states and load combinations according to EN 1990:2002 [27] and EN 1995-1-1:2004 [28] were considered. Reference material values were taken from EN 338:2016 [29] and for further assessment, visual inspection according to UNI11119:2004 (UNI) [30] was made in order to obtain a more specific interval of indicative values for the mechanical properties of the timber elements.

\section{RESULTS AND DISCUSSION}

\subsection{Self-weight calculation}

In the calculation of the self-weight of the structure using the simplified approach of measuring the overall cross-section of the different main parts of the structure such as the beams or thicknesses of the boards, but without taking into account details such as the decorative elements, a volume of $3.5 \mathrm{~m}^{3}$ was obtained. On the other hand, by using the 
data from the laser scanner survey a total volume of $5.3 \mathrm{~m}^{3}$ was calculated, which is significantly higher. Even if the simplified approach value is multiplied by a coefficient of 1.35 (coefficient related to the variation model of permanent loads such as self-weight according to EN1990:2002) the simplified approach is still an underestimation $\left(4.7 \mathrm{~m}^{3}\right)$. To verify that the value obtained by the laser scanner was accurate, all decorative details, such as the inverted pinnacles, frames and patterns were measured and the volume was calculated. Through this process a value of $5.26 \mathrm{~m}^{3}$ was obtained which is very similar to the value previously obtained by the laser scanner. This indicates that the use the combination of two clouds of points using sets of two targets separated by a vertical element with known distance allowed to accurately obtain the total value of the structure's volume for this case study.

The value of density for the timber elements was obtained through measuring of small size specimens according to standard ISO 13061-2:2014 [31]. The specimens were taken from an element that was disconnected from the structure on a previous intervention to the structure. The element was consistent in geometry and appearance with the elements of the timber ceiling. An average value of $430 \mathrm{~kg} / \mathrm{m}^{3}$ was found considering the full size sample with decay, whereas an average value of density of $470 \mathrm{~kg} / \mathrm{m}^{3}$ was found for nondecayed small specimens.

\subsection{Model simulation and safety assessment analysis}

Three different limit states were considered for the safety assessment analysis regarding two ultimate limit states and a service limit state. The ultimate limit states consist in the verification of the maximum tension and compression parallel to the grain stresses, while the service limit state corresponds to the maximum deflection of a timber ceiling beam. The formulation of EN 1995-1-1:2004 [28] was used considering a service class 2 (function of the relative air humidity and temperature measured onsite by a data logger for a period of one year),

For the structural assessment two hypothesis were considered to determine the material properties of the timber elements as it was not possible to remove structural size elements for mechanical testing. The first hypothesis considered the use of the indicative values of EN 338:2009 [29] with the timber strength class D18 being selected based on the density measurements. It must be noted that this class indicates a higher mean value of density 
than that obtained. For that reason and because we are dealing with existing timber elements, the values of D18 are taken only as indicative. Moreover, knowledge of only the density value is insufficient to attribute a class to a timber sample. Therefore, further data including visual inspection was considered using UNI 11119:2004 [30]. The class D18 indicates characteristic values of tension parallel to the grain strength of $f_{\mathrm{t}, 0, \mathrm{k}}=11$ $\mathrm{N} / \mathrm{mm}^{2}$ and compression parallel to the grain strength of $f_{\mathrm{c}, 0, \mathrm{k}}=18 \mathrm{~N} / \mathrm{mm}^{2}$. Following the formulation of EN 1995-1-1:2004 [28] the design strength values of tension parallel to the grain of $f_{\mathrm{t}, 0, \mathrm{~d}}=5.08 \mathrm{~N} / \mathrm{mm}^{2}$ and compression parallel to the grain of $f_{\mathrm{c}, 0, \mathrm{~d}}=8.31 \mathrm{~N} / \mathrm{mm}^{2}$ were obtained. However, as noted before more information besides density is required to have a proper indication of the strength class of the material. Therefore, since the case study corresponds to an existing old structure, a visual inspection was made aiming at a visual grading. The standard UNI 11119:2004 [30] was used and based on the conservation level of the structure and the number and size of defects, a visual grade I was considered. For this visual grade and timber species, the maximum stresses allowed in the application of admissible stresses methods regarding tension parallel to the grain strength is $f_{\mathrm{t}, 0}=11 \mathrm{~N} / \mathrm{mm}^{2}$ and for compression parallel to the grain strength is $f_{\mathrm{c}, 0}=11$ $\mathrm{N} / \mathrm{mm}^{2}$.

On the other hand, the service limit state regarding deformation of the structural elements, the limits indicated in EN 1995-1-1:2004 [28] were considered, namely L/300 and L/150 where $\mathrm{L}$ is the spam of an element. In this case, the main beams with a spam of $\mathrm{L}=4.4$ $\mathrm{m}$ were analysed as they were the elements with higher deformation, thus the limits are respectively of $14.7 \mathrm{~mm}$ and $29.3 \mathrm{~mm}$.

With respect to the global decay level and the results obtained for each face of the ceiling, the maximum and mean values of decay depth obtained by the drilling resistance tests are presented in Figure 10. For this case, the overall mean decay depth is approximately 8 $\mathrm{mm}$, whereas a maximum value of $30 \mathrm{~mm}$ was found in face VI. 


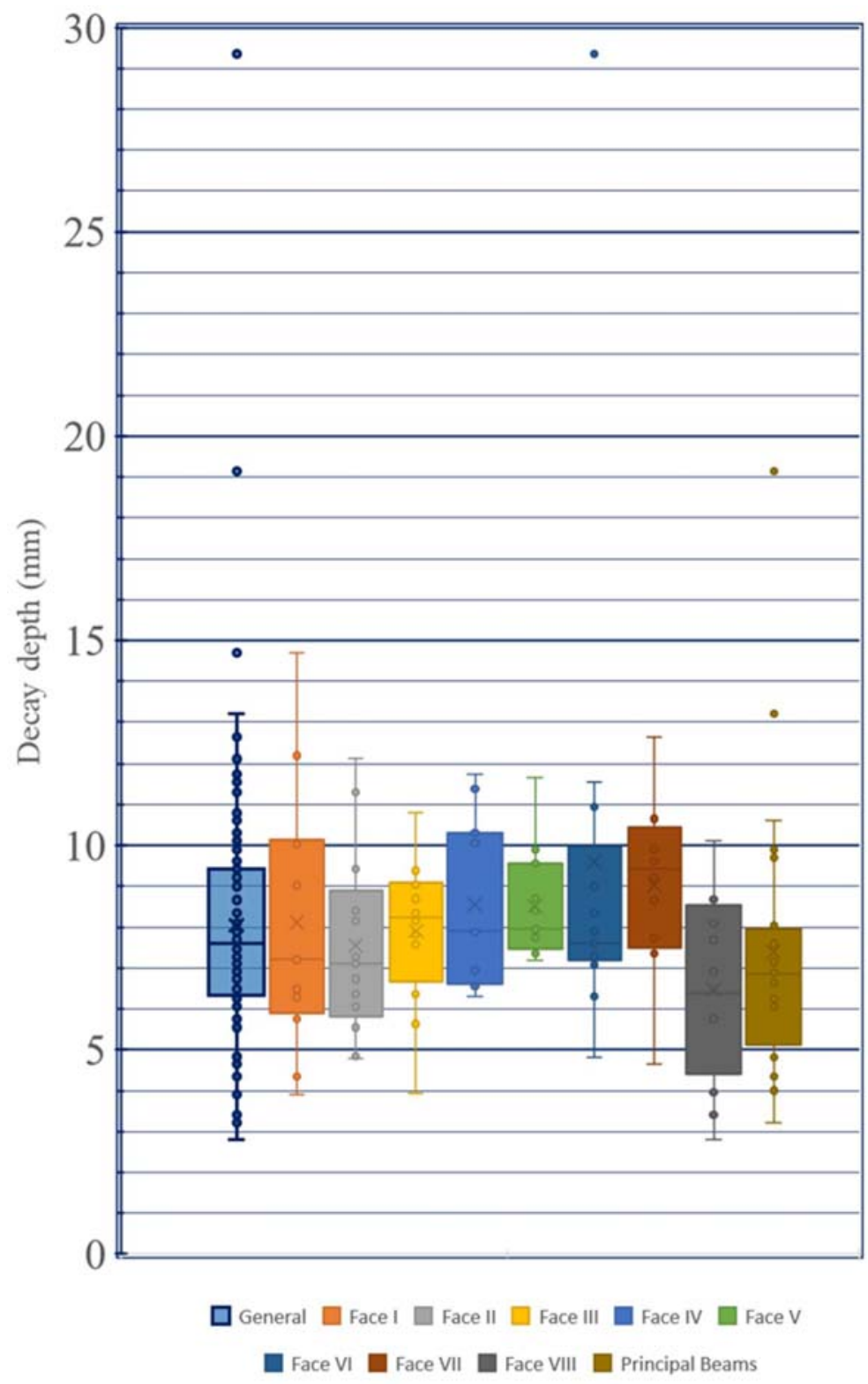

Figure 10: Box-plot graphs of the decay depth of the main beams obtained by drilling resistance tests for all and each faces of the ceiling.

Besides the structural safety analysis of the present condition of the ceiling, also an analysis was made regarding the progressive decrease of effective cross-section due to either the decay of all elements of the structure or if decay was only localized on a single face of the ceiling. For that purpose, the values of the cross-section were constantly decreased in the parametric model either globally or in a localized area of the model. 
The results of the safety assessment analysis are presented in Figure 11 where the first limit to be reached is the tension parallel to the grain strength for a decay level of $5.8 \mathrm{~mm}$ when decay is global, whereas for a localized decay on face VI a decay level of $7.7 \mathrm{~mm}$ would be needed to reach the limit state for tension parallel to the grain strength.

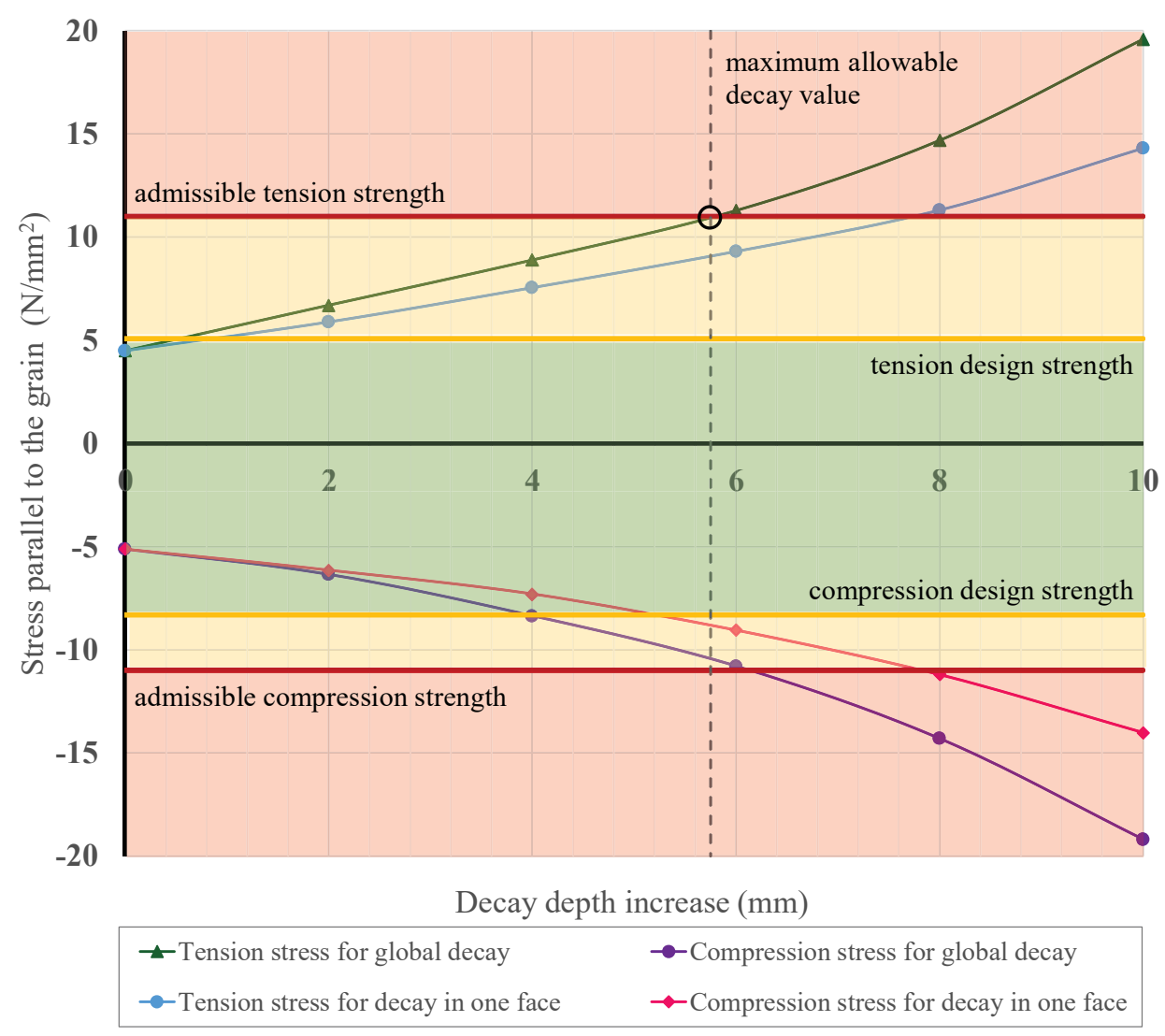

Figure 11: Stress values regarding a progressive decrease of effective cross-section due to decay. A null value of decay depth increase corresponds to the present condition.

With respect to the deformation, the lower limit state of $L / 300$ would be reached for a value of decay depth of $3.4 \mathrm{~mm}$ for global decay and $3.9 \mathrm{~mm}$ for localized decay in face VI, as presented in Figure 12. Regarding the increase of decay depth, the most conditioning limit state corresponds to the deformation of the structure. 


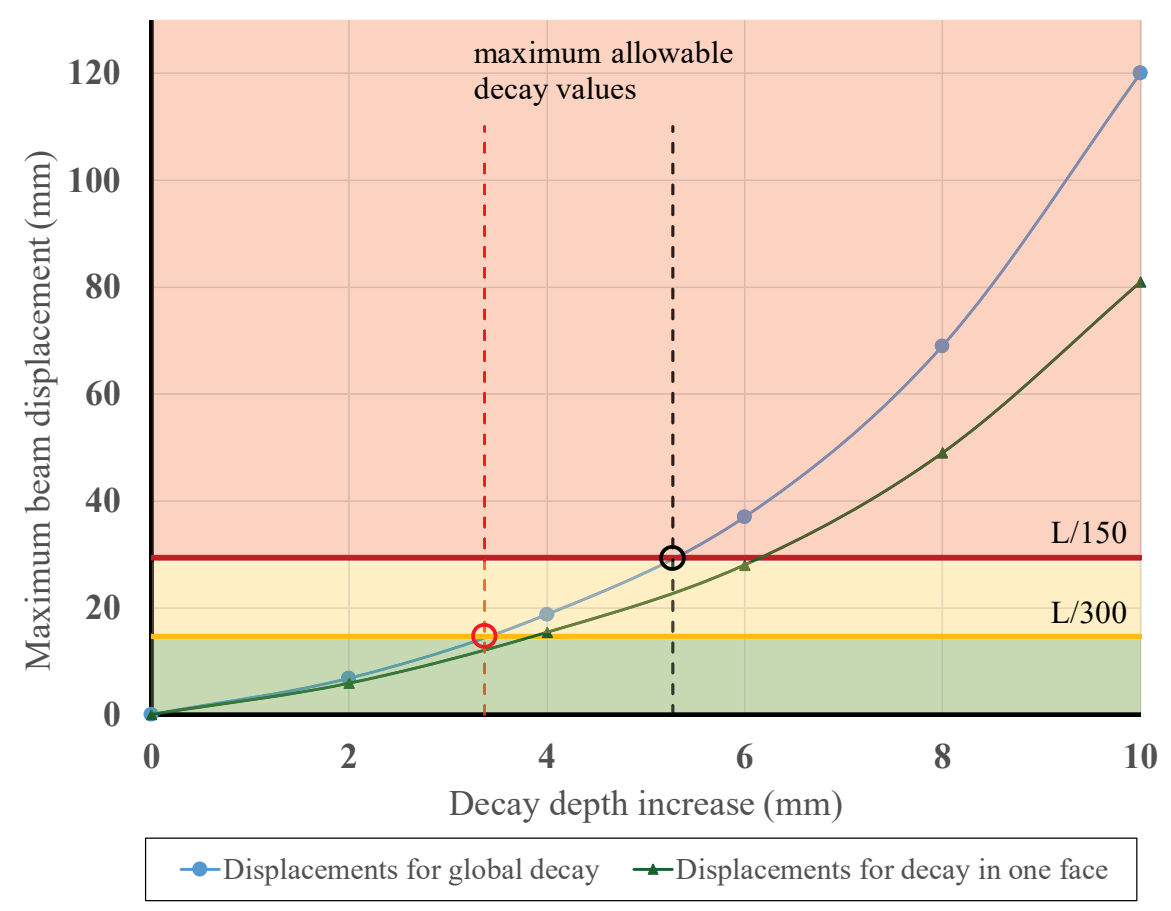

Figure 12. Maximum displacement values of the timber beams regarding a progressive decrease of effective cross-section due to decay. A null value of decay depth increase corresponds to the present condition.

\subsection{Prediction of performance regarding decay progression}

After obtaining the critical value for cross-section reduction it is important to predict when this event may occur if decay progresses. This prediction allows to delineate a better intervention and maintenance planning thus it is crucial for the preservation of the structure. However, it must be noted that a prediction of a possible failure time does not exclude that ordinary maintenance and regular inspections have to take place. To predict the period of time needed to reach failure it is needed to define the decay rate which largely depends on the boundary conditions of the structure. In this case, the value of decay rate was chosen considering the analysis of elements retrieved from an old structure also located in Portugal which comprised a timber floor structure, with chestnut wood elements, in similar exposure conditions [23]. Exposure conditions are related to the relative air humidity and temperature found on the surroundings of the structure. Temperatures of $5{ }^{\circ} \mathrm{C}$ up to $30^{\circ} \mathrm{C}$ are adequate for fungi growth, whereas fungi activity is latent below $5{ }^{\circ} \mathrm{C}$ and does not survive above $65^{\circ} \mathrm{C}$. With respect to moisture content, 
values below the fibre saturation point or above $80 \%$ of cell cavity filled with water are inadequate. Moreover, the position of the element, the orientation of the surfaces and also the connection with other elements are parameters taken into account in the decay model [25][26]. In [24], the decay rate was calibrated regarding the experimental campaign made with elements of a chestnut timber floor regarding the depth of decay and the age of the structure. Decay model parameters calibration was also made considering the conservation state found in onsite inspected timber structures of that nature. The used decay model corresponded to a bi-parametrical idealized model given by a bilinear function with two parameters, namely the time before noticeable decay starts and an annual decay penetration rate. These two parameters were calculated based on climate, durability, and structural conditions of the timber element. On that work, a decay rate of $0.13 \mathrm{~mm} /$ year was found, resulting from a mean decay depth of $10.35 \mathrm{~mm}$ obtained by pin penetration tests and consideration of a 100 years lifetime period.

By bearing in mind the prior simulations and the assumed decay rate, four scenarios are considered corresponding to the different limit states (ultimate and service) and the decay location (localized in one face or globally in all structure). Considering the limit state related to the deformation of the structure, an inadequate performance is reached with a $3.4 \mathrm{~mm}$ section loss for a global decay, which is predicted to happen after 26.2 years of constant decay. Whereas, an inadequate deformation performance is obtained with 3.9 $\mathrm{mm}$ decay loss if the decay process is localized in a single face predicted to happen after 30 years of decay. On the other hand, if considering only the ultimate limit state imposed when the tension parallel to the grain strength value is reached, a global decay scenario leads to an inadequate structural performance for a cross-section loss of $5.8 \mathrm{~mm}$ which, through the applied decay model, would happen after 44.6 years. Whereas, for a localized decay scenario the tension parallel to the grain strength is reached after a $7.7 \mathrm{~mm}$ crosssection loss corresponding to a prediction of 59.2 years before failure. The results are summarized in Table 1, where the cross-section loss limit corresponds to the thickness of decay, adding to the already existing decay thickness (Figure 10), needed to reach a given limit state.

It must be noted that it is assumed that the decay process would continue from the present moment and progress at a constant rate, which only happens if the conditions for decay development are favourable and no maintenance actions are taken. Although it is unlikely to have a homogeneous decay process on all faces of the structure, it is worth noticing 
that the prediction results indicate that in the case of a global decay phenomena, the structure would reach a structural failure condition after 18.5 years after reaching an inadequate deformation performance, whereas 29.2 years would take place between an inadequate deformation performance and failure in the case the decay is localized in a face of the structure. In this case, even if the time between infraction of the service and ultimate limit states can be used to consider urgent interventions, preventive maintenance should always take place before noticeable deformation is presented.

Table 1. Prediction of remaining years before reaching a given limit state, assuming a constant decay rate and added loss of cross-section.

\begin{tabular}{|c|c|c|c|c|c|}
\hline Scenario & $\begin{array}{l}\text { Decay rate } \\
(\mathrm{mm} / \text { year })\end{array}$ & $\begin{array}{l}\text { Decay } \\
\text { location }\end{array}$ & Limit state & $\begin{array}{l}\text { Cross-section } \\
\text { loss limit }(\mathrm{mm})\end{array}$ & $\begin{array}{l}\text { Prediction } \\
\text { time (years) }\end{array}$ \\
\hline 1.1 & 0.13 & global & deformation (service) & 3.4 & 26.2 \\
\hline 1.2 & 0.13 & local & deformation (service) & 3.9 & 30.0 \\
\hline 2.1 & 0.13 & global & $\begin{array}{l}\text { tension parallel to the } \\
\text { grain strength (ultimate) }\end{array}$ & 5.8 & 44.6 \\
\hline 2.2 & 0.13 & local & $\begin{array}{l}\text { tension parallel to the } \\
\text { grain strength (ultimate) }\end{array}$ & 7.7 & 59.2 \\
\hline
\end{tabular}

\section{CONCLUSIONS}

The present work evidenced the applicability of a methodology combining laser scanner and drilling resistance tests for geometrical survey and to use on 3D parametric models to assess the safety level of existing timber structures. This method allowed to assess the present condition, as well as analyse probable future performance of the structure if exposed to decay.

A case study was used to verify the applicability of the proposed method where also the use of a set of targets allowed to combine the bottom and top sides of a ceiling structure in order to accurately obtain its volume and consequent self-weight. Regarding the safety assessment of the Knights' Room timber ceiling structure it was found that, although the present condition presents an adequate level of structural safety regarding its self-weight, decay may lead to significant damage and a low safety level. Through numerical 
modelling and probabilistic simulation of the decay rate it was found that between 26 to 30 years, respectively for global or local decay, intervention measures would be required. Although the proposed model allowed to obtain a more accurate definition of possible intervention dates, the prediction time related to decay rates varies significantly according to the actual boundary conditions. Therefore, ordinary maintenance and regular inspection cannot be, by any means, disregarded.

Due to the parametric nature of the model, the applied methodology can be further expanded to include results from other tests of different nature, in order to either calibrate the existing information (update an existing parameter in the database) or to introduce new information on the model (creation of a new parameter in the database). For instance, information obtained by pin penetration tests, stress-wave techniques, hammer sounding and probing, among other tests, can help on a more precise definition of critical sections and decayed areas. Visual inspection can also be a tool to determine where are the sections/segments of the structure that require a higher level of information or detailing in the analysis, thus filtering the database to sections of the structure with more relevancy to the structural performance.

\section{ACKNOWLEGDGMENTS}

This work has been partially supported by the Spanish Ministry of Interior (Grant SPIP2017-02122), Spanish Ministry of Economy, Industry and Competitiveness (Grant: EUIN2017-87598), and Xunta de Galicia through grant ED431C2016-038. This work has been partially supported by Ministry of Science, Innovation and Universities of Spain through a mobility stay abroad «José Castillejo» (grant CAS18/00041). This work was partly financed by FEDER funds through the Competitivity Factors Operational Programme - COMPETE and by national funds through FCT Foundation for Science and Technology within the scope of the project POCI-01-0145-FEDER-007633. This work was partly financed by FEDER funds through the Competitivity and Internationalization

Operational Programme - COMPETE and by national funds through FCT - Foundation for Science and Technology within the scope of the project Invisible Woods (POCI-010145-FEDER-016843). The third author acknowledges the support of Protimber project (PTDC/ECM-EST/1072/2014) which was partly financed by national funds through FCT. 
The authors acknowledge the support of DGPC / Convento de Cristo in protocol with the University of Coimbra, for the permission and access to the Knight's Room.

\section{REFERENCES}

[1] Alessandri C, Mallardo V. Structural assessments of the Church of the Nativity in Bethlehem. J. Cult. Heritage 2012; 13:61-69.

[2] Macchioni N, Brunetti M,Pizzo B, Burato P, Nocetti M, Palanti S. The timber structures in the Church of the Nativity in Bethlehem: Typologies and diagnosis. Journal of cultural heritage 2012; 13:42-53.

[3] Bertolini-Cestari C, Invernizzi S, Spano A, Mallamaci L. Laser modeling and structural assessment of a XVIIth century wooden dome. Wiadomości Konserwatorskie 2012; 151-156.

[4] Bertolini-Cestari C., Spanò A., Invernizzi S., Marzi T. Retrofitting Assessment and Numerical Models for the Historical Timber Roof Structures of the Towers of Valentino Castle in Turin. In: Cruz H., Saporiti Machado J., Campos Costa A., Xavier Candeias P., Ruggieri N., Manuel Catarino J. (eds) Historical EarthquakeResistant Timber Framing in the Mediterranean Area. Lecture Notes in Civil Engineering, vol 1. Springer, Cham. 2016. pp. 321-333. doi.org/10.1007/978-3319-39492-3_27.

[5] Bertolini-Cestari C., Spanò A., Invernizzi S., Donadio E., Marzi T., Sammartano G.bThe Role of Terrestrial LiDAR for Mechanical and Safety Evaluation of Historic Timber Floors. In: Cruz H., Saporiti Machado J., Campos Costa A., Xavier Candeias P., Ruggieri N., Manuel Catarino J. (eds) Historical EarthquakeResistant Timber Framing in the Mediterranean Area. Lecture Notes in Civil Engineering, vol 1. Springer, Cham. 2016. pp. 277-286. doi.org/10.1007/978-3319-39492-3_23.

[6] Bassier M, Hadjidemetriou G, Vergauwen M, Van Roy N, Verstrynge E. Implementation of Scan-to-BIM and FEM for the documentation and analysis of heritage timber roof structures. In: Euro-Mediterranean Conference 2016;79-90.

[7] Pöchtrager M, Styhler-Aydın G, Döring-Williams M, Pfeifer N. Digital reconstruction of historic roof structures: developing a workflow for a highly automated analysis. Virtual Archaeology Review 2018.

[8] Brashaw BK, Anderson S, Ross RJ. Laser Scanning Technology as Part of a Comprehensive Condition Assessment for Covered Bridges. USDA Forest Service, Forest Products Laboratory, Research Note, FPL-RN-0335, 2015; 12 pp.

[9] Betti M, Vignoli A. Numerical assessment of the static and seismic behaviour of the basilica of Santa Maria all'Impruneta (Italy). Construction and Building Materials 2011; 25:4308-4324.

[10] Oreni D, Brumana R, Cuca B, Georgopoulos A. HBIM for conservation and management of built heritage: Towards a library of vaults and wooden bean floors. Remote Sens. Spatial Inf. Sci 2013; 164:1-6. 
[11] Cabaleiro M, Riveiro B, Arias P, Caamaño JC. Algorithm for the analysis of the geometric properties of cross-sections of timber beams with lack of material from LIDAR data. Materials and Structures 2016; 49:4265-4278.

[12] Cabaleiro M, Hermida J, Riveiro B, Caamaño JC. Automated processing of dense points clouds to automatically determine deformations in highly irregular timber structures. Construction and Building Materials 2017; 146:393-402.

[13] Cabaleiro M, Lindenbergh R, Gard WF, Arias P, van de Kuilen JWG. Algorithm for automatic detection and analysis of cracks in timber beams from LiDAR data. Construction and Building Materials 2017; 130:41-53.

[14] Sousa HS, Sørensen JD, Kirkegaard PH, Branco JM, Lourenço PB. On the use of NDT data for reliability-based assessment of existing timber structures. Engineering Structures 2013; 56:298-311.

[15] Feio A, Machado JS. In-situ assessment of timber structural members: Combining information from visual strength grading and NDT/SDT methods-A review. Construction and Building Materials 2015; 101:1157-1165.

[16] Ilharco T, Lechner T, Nowak T. Assessment of timber floors by means of nondestructive testing methods. Construction and Building Materials 2015; 101:12061214.

[17] Nowak TP, Jasieńko J, Hamrol-Bielecka K. In situ assessment of structural timber using the resistance drilling method-evaluation of usefulness. Construction and Building Materials 2016; 102:403-415.

[18] Branco JM, Sousa HS, Tsakanika E. Non-destructive assessment, full-scale loadcarrying tests and local interventions on two historic timber collar roof trusses. Engineering Structures 2017; 140:209-224.

[19] Frontini F. In situ evaluation of a timber structure using a drilling resistance device. Case study: Kjøpmannsgata 27, Trondheim (Norway). International Wood Products Journal 2017; 8:14-20.

[20] Bergamasco I, Marzo A, Marghella G, Carpani B. In-situ experimental campaign on the covering structures of "Villa dei Misteri" in Pompeii. Journal of Civil Structural Health Monitoring 2018; 8:181-197.

[21] Lourenço PB, Sousa HS, Brites RD, Neves LC. In situ measured cross section geometry of old timber structures and its influence on structural safety. Materials and Structures 2013; 46:1193-1208.

[22] Cabaleiro M, Branco JM, Sousa HS, Conde B. First results on the combination of laser scanner and drilling resistance tests for the assessment of the geometrical condition of irregular cross-sections of timber beams. Materials and Structures 2018; 51(4):99.

[23] Brites RD, Neves LC, Machado JS, Lourenço PB, Sousa HS. Reliability analysis of a timber truss system subjected to decay. Engineering Structures 2013; 46:184192.

[24] Sousa HS, Branco JM, Lourenço PB. Characterization of cross sections from old chestnut beams weakened by decay. International Journal of Architectural Heritage 2014; 8(3):436-451. 
[25] Leicester RH. Engineered durability for timber construction. Progress in Structural Engineering and Materials 2001; 3:216-227.

[26] Leicester RH, Wang CH, Nguyen MN, MacKenzie CE. Design of exposed timber structures. Australian Journal of Structural Engineering 2009; 9:217-224.

[27] CEN (2002) EN 1990:2002, Eurocode 0: Basis of Structural Design, European Committee for Standardization, Brussels.

[28] CEN (2004) EN 1995-1-1:2004, Eurocode 5: design of timber structures. Part 11: General common rules and rules for buildings, CEN European Committee for Standardization, Brussels.

[29] CEN (2016) EN 338:2016, Structural timber. Strength classes, CEN European Committee for Standardization, Brussels.

[30] UNI (2004) UNI 11119:2004 Cultural Heritage - Wooden artefacts - Load-bearing structures - On site inspections for the diagnosis of timber members. UNI Milano

[31] ISO (2014). ISO 13061-2:2014 - Physical and mechanical properties of wood -Test methods for small clear wood specimens -- Part 2: Determination of density for physical and mechanical tests. International Organization for Standardization, Geneva. 